\title{
Mapping the pigment distribution of Vermeer's Girl with a Pearl Earring
}

\author{
John K. Delaney ${ }^{1 *}$, Kathryn A. Dooley ${ }^{1}$, Annelies van Loon ${ }^{2,3}$ and Abbie Vandivere ${ }^{2}$
}

\begin{abstract}
As part of the 2018 Girl in the Spotlight project, reflectance and molecular fluorescence imaging spectroscopy (RIS, FIS), and macroscale X-ray fluorescence scanning (MA-XRF) were performed on Johannes Vermeer's Girl with a Pearl Earring (c. 1665, Mauritshuis) with the goal of obtaining a comprehensive understanding of the distribution of pigments. Prior analysis of cross-sections in the 1990s, and their recent (re)-examination identified many of the pigments present in the painting. The results from all three imaging methods, along with site-specific fibre optic reflectance spectroscopy, confirmed Vermeer's limited palette and determined how and where each pigment was used. RIS and MA-XRF found the blue region of the headscarf was painted with natural ultramarine and varying amounts of lead white. The yellow part of the headscarf was painted with yellow ochre and lead white, and the border of the headscarf additionally contained ultramarine and lead-tin yellow. The lit side of the jacket was painted with yellow ochre, lead white, and ultramarine, whereas the darker, ruddy blue-green areas that are in relative shadow contained yellow ochre with ultramarine. FIS also mapped a red lake in portions of the shadowed areas at the back of the jacket. The Girl's skin was painted using earths (ochres), lead white, vermilion, and some red lake. Fluorescence emission from red lake was strongest in the lips, where vermilion was also found. The pearl earring was depicted using a scumble and highlight of lead white. In the dark background, the RIS data cube allowed the determination of the visible spectral shape even though the overall reflectance intensity was low (1 to 3\%). A reflectance inflection point at $\sim 700 \mathrm{~nm}$ indicated the presence of indigo, whereas lack of a reflectance peak at green wavelengths in most areas indicated degradation of the yellow pigment previously identified as weld. Some small green areas in the background (i.e. reflectance maximum at $525 \mathrm{~nm}$ ) were found; these coincided with areas previously protected by old retouchings, and are thus better preserved. The combination of all three spectral imaging modalities provided a more complete understanding of how the colouration of the painting was achieved.
\end{abstract}

Keywords: Reflectance imaging spectroscopy, Fluorescence imaging spectroscopy, X-ray fluorescence, MA-XRF, Pigment, Vermeer

\section{Introduction}

A wealth of information can be derived from paintings by visual inspection of the paint surface, both with and without magnification. Additional information comes through visual examination of technical images, including: photographs collected with ultraviolet radiation, $\mathrm{X}$-ray radiographs (X-radiographs), and broadband

\footnotetext{
*Correspondence: j-delaney@nga.gov

${ }^{1}$ Scientific Research Department, National Gallery of Art, 6th and

Constitution Avenue NW, Washington, DC 20565, USA

Full list of author information is available at the end of the article
}

infrared reflectograms (IRR). Such visual examinations using different regions of the electromagnetic spectrum provide insight into the painterly process used for creating the painting, as well as its state of preservation. The results of these analyses lead to a working model of the specific steps taken during the painting process and the materials that the artists used; however, some questions, such as the identity of specific pigments, cannot be answered by careful looking alone. The collection and study of microsamples, in the form of cross-sections or scrapings from the paint surface, can help address these shortcomings. The analysis of samples can provide

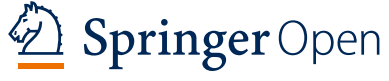

(c) The Author(s) 2020. This article is licensed under a Creative Commons Attribution 4.0 International License, which permits use, sharing adaptation, distribution and reproduction in any medium or format, as long as you give appropriate credit to the original author(s) and the source, provide a link to the Creative Commons licence, and indicate if changes were made. The images or other third party material in this article are included in the article's Creative Commons licence, unless indicated otherwise in a credit line to the material. If material is not included in the article's Creative Commons licence and your intended use is not permitted by statutory regulation or exceeds the permitted use, you will need to obtain permission directly from the copyright holder. To view a copy of this licence, visit http://creativeco mmons.org/licenses/by/4.0/. The Creative Commons Public Domain Dedication waiver (http://creativecommons.org/publicdomain/ zero/1.0/) applies to the data made available in this article, unless otherwise stated in a credit line to the data. 
conclusive information about the paint stratigraphy and the pigments present at the sites where they were taken. However, the inability to sample in pristine areas,-or to sample systematically in different colour areas-nearly always leave some important questions unresolved, and the extrapolation of localised results is not necessarily representative of broad areas.

To address this issue, non-invasive analysis methods have been utilised to collect information at more sites on the painting. Numerous non-invasive techniquesincluding X-ray fluorescence (XRF) spectroscopy, fibre optic reflectance spectroscopy (FORS), molecular fluorescence spectroscopy, Raman spectroscopy, and mid-IR reflectance spectroscopy-have been adapted as point measurement techniques for use on cultural heritage objects. However, not enough sites are typically measured to allow statistical analysis to determine the distribution of artist materials across a painting. For this reason, the desire to map compositional information across the entire painting has driven the development and application of macroscale imaging spectroscopy methods over the last decade.

Two macroscale imaging modalities, including reflectance (in the visible and near-infrared) imaging spectroscopy (RIS), and X-ray fluorescence imaging spectroscopy-also known as macroscopic XRF (MA-XRF) - are now being used by both academic and museum researchers. The combined use of both RIS and MA-XRF have provided a clearer understanding of the distribution of pigments used in Cosimo Tura's The Annunciation with Saint Francis and Saint Louis of Toulouse, c. 1470/1480 [1], and have shown that stylistic differences observed in paint handling are connected to material differences in Saul and David by Rembrandt, c. 1651-1654 and c. 1655-1658 [2]. Pigments have also been identified through the combined use of MA$\mathrm{XRF}$ and RIS in the mid-infrared spectral region from an unvarnished, twentieth century folk-art painting [3]. The results from these studies could not have been achieved with a single technique alone. Macroscale spectral imaging modalities have also been applied to Giovanni Bellini's Feast of the Gods, 1514/1529, which had already undergone extensive analysis in the late 1980s using cross-sections, X-radiography, and infrared reflectography [4]. Collectively, RIS and MA-XRF provided information that answered outstanding questions related to possible changes Bellini made to the figures, as well as allowed for a detailed simulation of what the painting looked like before Bellini's background of trees was revised by Dosso Dossi and later by Titian [5]. Thus, even if a painting has been previously studied, macroscale spectroscopic imaging methods can still prove useful. The application of such methods to Johannes Vermeer's painting Girl with a Pearl Earring-also previously studied $[6,7]$ - was a logical next step.

Several complementary macroscale and microscale imaging methods were used to develop a deeper understanding of Johannes Vermeer's Girl with a Pearl Earring (c. 1665, Mauritshuis), as part of the Girl in the Spotlight research project undertaken in 2018 [8]. Previous research into the pigments, carried out during the 1994 restoration treatment, was based primarily on analyses of samples mounted as cross-sections, and focused on the materials used in her jacket and the background [6, 7]. The 1998 publication by Groen et al. [6] lists the pigments identified in cross-sections as an appendix. Based on microscopic examination of these samples, the upper layer of the Girl's yellow jacket were found to contain: lead white, yellow and brown ochres, ultramarine, black, and an organic red lake. Further analysis using high performance liquid chromatography (HPLC) was needed to characterise the colourants in the glaze in the background: weld and indigo. The yellow part of the Girl's headscarf contained lead white and yellow ochre. The pigments in other colour areas-her lips, earring, and blue headscarf-were not sampled in the 1990s. Furthermore, the original locations of some of the samplesincluding one from the Girl's skin-was unclear, as they were collected as dislodged fragments [6]. Some of the samples taken in the 1990s were re-analysed as part of the 2018 Girl in the Spotlight research project [7].

Although the analyses of cross-sections in the 1990s provided valuable information about the pigments, their microsamples were restricted to specific (sometimes unidentified) spots of Girl with a Pearl Earring. The goal of the macroscale analyses described in the current paper was to provide material maps to allow a more complete understanding of the distribution of these pigments. To achieve this, visible-to-near-infrared RIS, in conjunction with MA-XRF maps, were used to identify and map pigments throughout the entire painting. Because of the differences in penetration depths between the two methods, the combination of visible RIS and MA-XRF also can provide some information about the layer structure. In addition, visible fluorescence imaging spectroscopy (FIS) was used to map the distribution of a red lake pigment that could not be surmised from a limited number of samples, or adequately mapped with either RIS or MA-XRF. The colour properties of the dark glaze in the background was also investigated. Mapping the distribution of pigments in Girl with a Pearl Earring with complementary imaging modalities (and supplemented with FORS spectra at discrete sites) has expanded upon what was previously known about the pigments that Vermeer used to create this iconic painting. 


\section{Results and discussion}

This paper presents the results of macroscale imaging spectroscopy and pigment assignments for specific areas of Girl with a Pearl Earring, including: the skin and lips, pearl earring, headscarf, jacket, and background. RIS was performed using two hyperspectral cameras, one operating in the visible-to-NIR (VNIR, 400-1000 nm, $2.4 \mathrm{~nm}$ sampling) and the other further into the NIR (967-1680 nm, 3.4 nm sampling). FIS was performed using either an ultraviolet lamp or blue-green excitation light (460-532 nm) and the VNIR hyperspectral camera. The reflectance and fluorescence mosaicked final image cubes, along with the first derivative (with respect to wavelength) cube, were processed using convex geometry algorithms (see "Experimental methods" section) to find reflectance and fluorescence spectral endmembers that best described the image cubes. The identification of the pigment or pigments was done by interpreting spectral features in the endmembers' reflectance or fluorescence spectra and elements present in the MA-XRF maps. To aid in the assignment, FORS measurements
(350 to $2500 \mathrm{~nm}$ ) were collected from sites defined by the RIS, FIS, or elemental maps.

\section{Skin and lips}

The combination of RIS and MA-XRF analyses provided information about the distribution of pigments within the Girl's face (Fig. 1). The effect of layering and mixing pigments resulted in similar reflectance spectra, showing small variations in their spectral shape. To enhance the separation of pigments with overlapping spectral features, the first derivative of the RIS image cube, with respect to wavelength, was used. A false-colour first derivative image (Fig. 1b) shows a material separation between the left and right cheek, which appear mainly pink or green, respectively. In order to map these material differences, spectral endmembers were found. The first endmember ('red' spectrum, Fig. 1b inset) has a symmetrical peak at $583 \mathrm{~nm}$ and a full width at half maximum (FWHM) of $47 \mathrm{~nm}$. These spectral features coincide with those of vermilion (typically $\sim 580$ to $600 \mathrm{~nm}$ and FWHM $40 \mathrm{~nm}$ ) [9]. The second endmember ('blue'
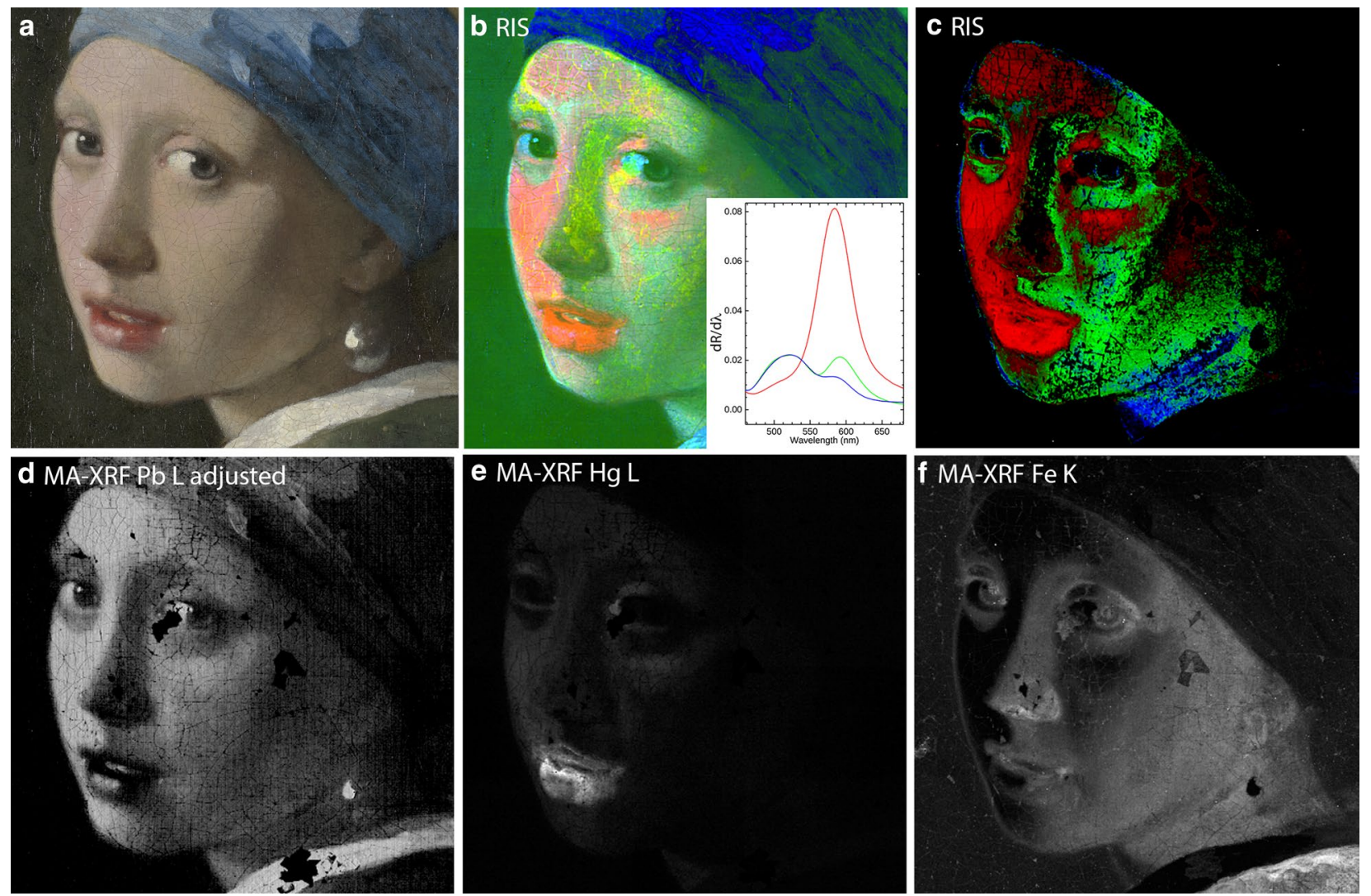

Fig. 1 a Visible light detail of the Girl's face. René Gerritsen Art \& Research Photography; b false-colour first derivative of the reflectance cube image (RGB: 600,540 , and $450 \mathrm{~nm}$ ), inset shows first-derivative endmember spectra used to make the maps in $\mathbf{c}$; $\mathbf{c}$ maps of the first derivative spectral endmembers, 'red'= mainly vermilion, 'green'= ochre with vermilion, and 'blue'= mainly ochre; $\mathbf{d}$ MA-XRF map of lead (Pb L) with intensity adjusted to emphasise presence of lead in the face rather than the background; e MA-XRF map of mercury ( $\mathrm{Hg} L$ ); $\mathbf{f}$ MA-XRF map of iron (Fe K) 
spectrum) has the characteristic shape of an ochre pigment, while the third endmember ('green' spectrum) has spectral features of both ochre and vermilion. It should be noted that even the first endmember ('red') has weak spectral features associated with ochre. The RIS maps (Fig. 1c) show that vermilion (and a small amount of ochre) are present in the lips, forehead, left cheek (the Girl's proper right cheek), and in specific areas on the right (shadow) side of the face. The 'green' endmember, having spectral characteristics of both vermilion and ochre, maps to most of the right side of her face, and directly around the left eye (her proper right eye). The 'blue' endmember, which shows spectral features dominated by ochre, maps to a few areas on her neck. Examination of the reflectance image cube (400-1680 nm) found that in areas where the ochre was most pure, the spectral features (a broad absorption at $\sim 950 \mathrm{~nm}$ and a reflectance transition edge at $\sim 520 \mathrm{~nm}$ ) are more consistent with goethite $\left(\alpha-\mathrm{Fe}^{3+} \mathrm{O}(\mathrm{OH})\right.$,) rather than hematite $\left(\mathrm{Fe}_{2} \mathrm{O}_{3}\right)[10,11]$. In summary, on the left (lit) side of the face, more vermilion is present than ochre, whereas on the right (shadow) side, more ochre and less vermilion was found. Since the spectral features used for mapping occur in the visible spectral region, they represent the pigment distribution near the painting's surface. In contrast, it is expected that MA-XRF maps should include signal from both the surface and lower paint layers, except for low energy emission lines.

The MA-XRF maps of the elements likely associated with lead white (lead, $\mathrm{Pb} \mathrm{L}$ ), vermilion (mercury, $\mathrm{Hg} \mathrm{L}$ ), and ochre (iron, Fe K) (Fig. 1d-f) are generally consistent with the RIS maps. However, in the areas of the skin where more mercury and lead are present (e.g. the leftlit-side of the face), the MA-XRF iron map shows less emission intensity from iron, even though iron ochre was identified in the reflectance/first derivative spectra. A cross-section from the forehead [12] identified a small amount of iron ochre in the surface layer, and more iron ochre in the sub-surface layer beneath the mercury- and lead-containing paint. Hence, the low intensity of iron in this region in the MA-XRF map could be the result of mercury and lead absorbing some of the X-ray excitation irradiance, thus effectively reducing the amount of iron that is excited. This underscores the importance of considering matrix effects when relating XRF intensity to the amount of an element, analogous to the way that absorption by true black pigments can affect the reflectance intensity of RIS spectral features.

Direct evidence for red lake pigments was not observed in the flesh tones using RIS; however, with higher signal-to-noise FORS measurements, sites in the lips were found to have two weak absorption bands in the visible spectral region indicative of a red lake [13]
Indirect evidence for the presence of a lake pigment can be found in the MA-XRF potassium (K) map (Fig. 2c) in which increased emission intensity occurs in the lips. The potassium in this region is inferred to be from the substrate of a lake pigment, although it also could be associated with natural ultramarine, green earth, smalt, or an iron earth pigment.

To look for any direct evidence of the presence of a red lake pigment in the Girl's skin, molecular FIS was employed. In other studies, FIS has been used to identify and map madder lake in an encaustic painting [14], and site-specific fluorescence spectroscopy has been used to identify carmine lake [15]. Here, the FIS analysis was done using one of two excitation sources to induce the fluorescence emission. The first was a standard UV lamp used for examining paintings, which can excite lake pigments as well as aged varnish, binding medium, or degradation products from the binding medium and pigments. The second excitation source was a slide projector equipped with spectral filters that limited the illumination to blue-green light from 460 to $532 \mathrm{~nm}$ in order to preferentially excite red lake pigments. The UVinduced and blue/green-induced fluorescence image cubes revealed some fluorescence spectra with emission maxima from $\sim 600$ to $620 \mathrm{~nm}$, suggesting the presence of a red lake. Some fluorescence spectra showed a broad emission that decreased in intensity with increasing wavelength, suggesting an emission maximum outside the collected spectral range (i.e. peak emission occurring at less than $550 \mathrm{~nm}$ ). This emission spectral component was more prevalent in areas of white paint and was also detected more frequently in the emission image cube excited with UV, rather than blue-green, light. As a result, this UV-induced emission was attributed to fluorophores associated with degradation products related to aged oil and lead white, and not from a red lake.

Molecular fluorescence maps were made using the first derivative FIS image cubes and endmembers that were selected manually. For the FIS image cube collected with UV excitation light, only one first derivative endmember was recovered (Fig. 2f) and it was used to make the map shown in Fig. 2b. This endmember maps to most of the red lips of the Girl, and a small part of her nostril and the nodule at the inner corner of her eye. The fluorescence spectrum of this endmember has an emission maximum at $599 \mathrm{~nm}$ ('blue' spectrum, Fig. 2e). For the FIS image cube collected with blue-green excitation light, two first derivative endmembers ('pink' and 'red' spectra, Fig. 2g) were used to make the map in Fig. 2d. The 'red' endmember also maps to the lips and the area near the nostril of the Girl, and the 'pink' endmember maps to the skin around her mouth and her proper left cheek. The associated fluorescence spectra (Fig. 2e) show emission 

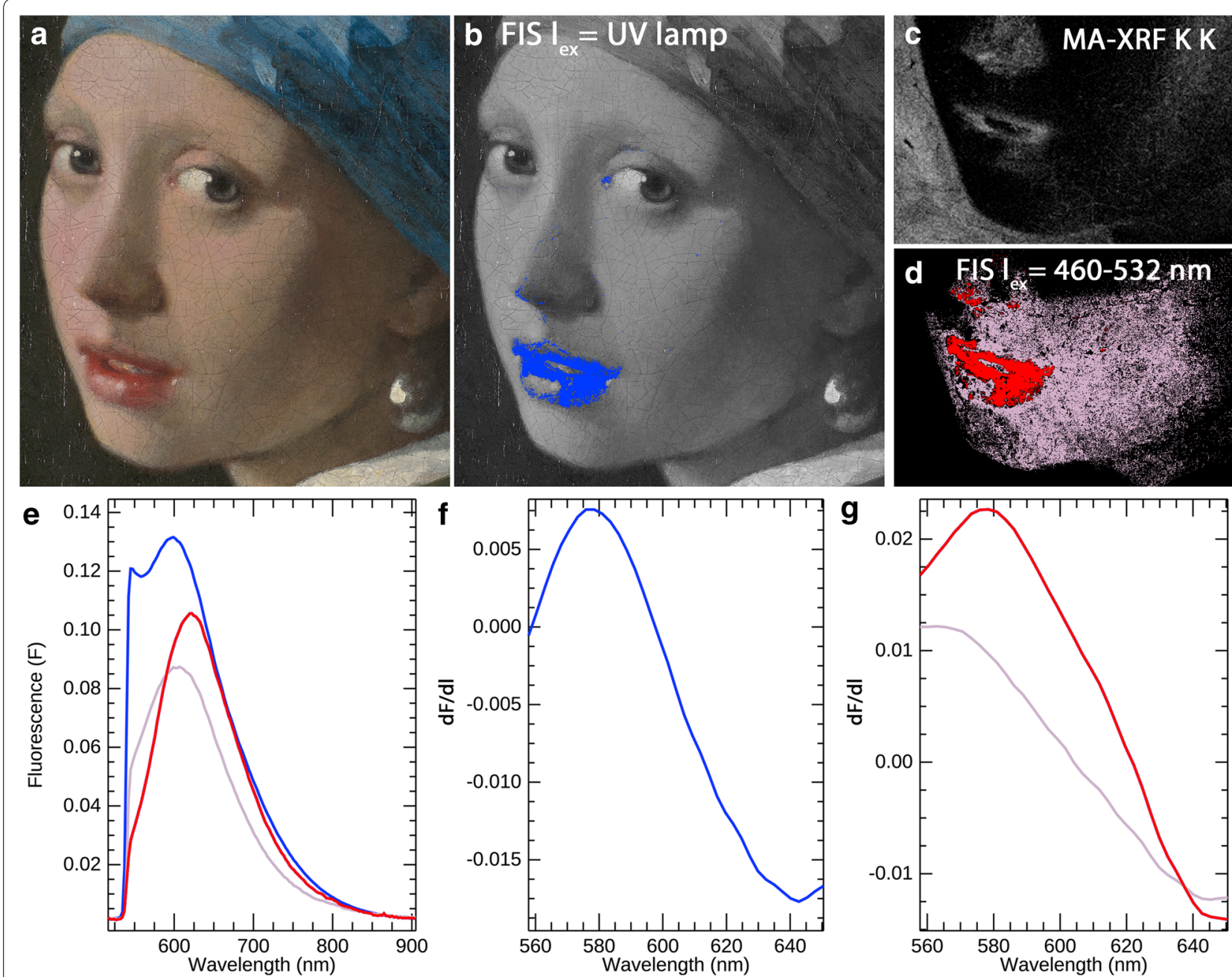

Fig. 2 a Visible light detail of the Girl's face. René Gerritsen Art \& Research Photography; b Map of fluorescence spectral endmember ('blue') showing red lake fluorescence obtained with UV excitation source. The corresponding first derivative endmember spectrum used for the map is shown in $\mathbf{f}$; c MA-XRF map of potassium (K K); $\mathbf{d}$ Map of two fluorescence spectral endmembers ('red'and 'pink') showing red lake fluorescence obtained with excitation at 460-532 nm. The corresponding first derivative endmember spectra used for the map are shown in $\mathbf{g} ; \mathbf{e}$ average fluorescence spectra of the same pixels used to define the 'blue,',red', and 'pink' first derivative endmember spectra

maxima at $620 \mathrm{~nm}$ ('red' spectrum) and $604 \mathrm{~nm}$ ('pink' spectrum).

Comparison of the results obtained using two different excitation sources shows the fluorescence emission spectra collected with blue-green excitation light emit much less fluorescence between the cut-on wavelength $(533 \mathrm{~nm})$ and $600 \mathrm{~nm}$ than the spectra collected with UV excitation light. This suggests that the measured molecular fluorescence is dominated by emission from a red lake, since red lakes strongly absorb blue-green light, rather than being dominated by the broad emission associated with degradation products noted above. While the 'red'-coloured endmember obtained using the blue-green excitation maps to the same areas of the lips as the 'blue'-coloured endmember obtained using UV excitation, only excitation with blue-green light was able to map the fluorescent component with a lower emission intensity in the Girl's cheek (the 'pink'-coloured endmember). This comparison between spectra collected with different excitation spectral regions shows the importance of using excitation wavelengths that preferentially excite the target of interest in order to ensure the most accurate and robust emission spectra. The results from excitation with blue-green light support the presence and distribution of a red lake in the lips and the face of the Girl.

As to the identity of the red lake(s), some information can be inferred from the fluorescence spectral shapes and emission maxima and also from positions 
of the absorption sub-bands in the reflectance spectra. In the lips, the observed emission maximum is shifted towards the red part of the visible spectrum; the intensity is stronger compared to emission from the cheeks. Although the range of the observed emission maxima is consistent with the presence of madder or insect-based red lakes [16], the identification of specific red lake(s) cannot be made from this data since no fluorescence self-absorption correction was done. Self-absorption increases with red lake concentration resulting in an artificial shift of the emission maximum that hinders assignment of the pigment. However, as noted above, weak absorption features in the FORS reflectance spectra were observed in the lips where the fluorescence was the strongest. In ten FORS measurements from sites within the lips, subtle absorption features at $529 \mathrm{~nm}$ and $564 \mathrm{~nm}$ in continuum-removed spectra were observed indicating the presence of an insect-based red lake (with an aluminium substrate), such as cochineal or lac.

\section{Pearl earring}

Close visual inspection shows that the shape of the pearl earring is an illusion: no drawn or painted outlines were detected, nor is there a hook to hang the earring from the Girl's ear. The shape of the pearl is depicted with a whitish scumble applied over the shadow of the Girl's neck (Fig. 3a). The white teardrop-shaped highlight on the left of the pearl, as well as the thinly applied scumble at the bottom of the pearl, which depicts the reflection of the Girl's white collar, are visible in the MA-XRF Pb M map (Fig. 3b), which is indicative of lead closer to the surface. In contrast, the MA-XRF map for Pb L (Fig. 3c) is dominated by paint layers below the surface and shows only the highlight, likely because the paint of the highlight is thick. For a similar reason, infrared RIS detects just the highlight of the pearl. Reflectance spectra from hydrocerussite (basic form of lead white) show an absorption feature near $1449 \mathrm{~nm}$, attributable to hydroxyl $(\mathrm{OH})$ stretching. The RIS map of this $1449 \mathrm{~nm}$ absorption feature is shown in Fig. 3d, within which the highlight is visible. This indicates that the scumble was applied on the upper surface of the paint layers, as a finishing touch.

\section{Blue part of headscarf}

The blue pigment in the Girl's headscarf was assumed to be ultramarine, since Vermeer is known to have extensively used ultramarine in other paintings from his oeuvre [17, 18]. Analysis of the RIS cube recovered three reflectance endmember spectra that defined the blue headscarf (Fig. 4b, c). Each endmember has a reflectance peak in the blue $(468-480 \mathrm{~nm})$ with a strong absorption at $600 \mathrm{~nm}$ (Fig. 4c), indicative of ultramarine (natural or synthetic) [19]. All endmembers show

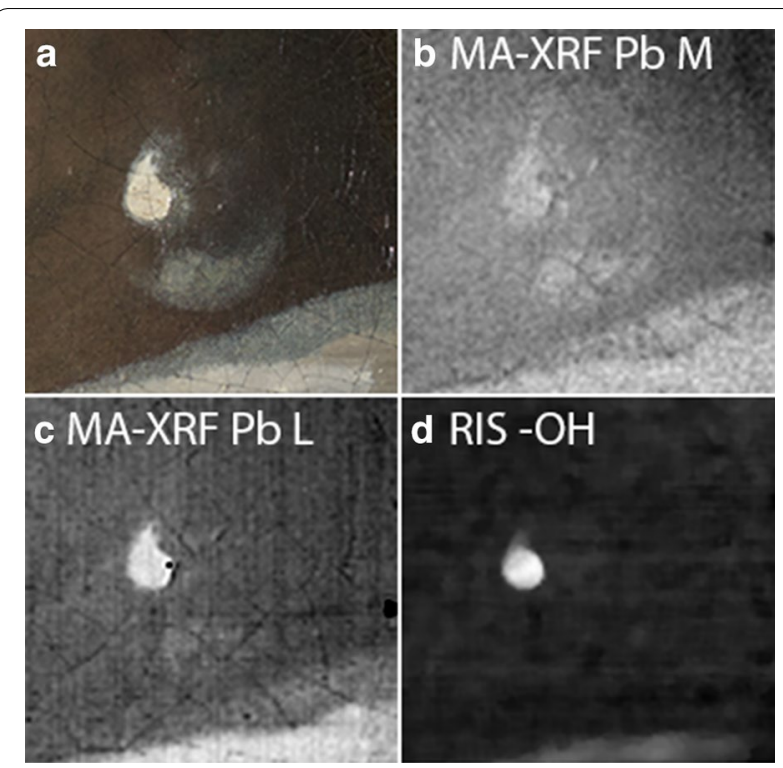

Fig. 3 a Visible light detail. René Gerritsen Art \& Research Photography; $\mathbf{b}$ MA-XRF map of lead (Pb M); c MA-XRF map of lead $(\mathrm{Pb} \mathrm{L})$; d RIS map of hydroxyl absorption feature near $1449 \mathrm{~nm}$ indicative of basic lead white

a narrow absorption feature at $1449 \mathrm{~nm}$, attributable to the hydroxyl $(\mathrm{OH})$ group in hydrocerussite (basic lead white).

Thus, the lightest-appearing blue paint on the top of the headscarf (Fig. 4a) contains the most lead white ('green' endmember, Fig. 4b, c). The darkest blue paint in the headscarf contains the least amount of lead white ('blue' endmember, Fig. 4b, c). All three endmember spectra show a decreasing reflectance with increasing wavelengths in the NIR. The steeper slopes occur for paints containing more lead white. Neither ultramarine nor lead white absorb in the NIR (750-2500 nm). Lead white has a higher refractive index (2) than ultramarine (1.5) and the binding media (1.48), which causes it to scatter light more efficiently. As a result, the reflectance spectra in the NIR are expected to be dominated by Mie scattering (i.e. the scattering decreases with increasing wavelength) as well as the absorbance properties of the paint layer(s) beneath. At longer wavelengths where the scattering from lead white is low, the optical properties of the paint layer below begin to dominate. If the paint layer below is highly reflective, then little change in the NIR reflectance should be observed. If the underlayer is absorbing in the NIR, then the NIR reflectance should decrease, as is observed here. These results are in agreement with earlier findings about the underlayers beneath the headscarf: a black underpaint is present beneath the shadow part, and the left (lit) side was painted directly onto the grey ground, which contains carbon black [20]. 

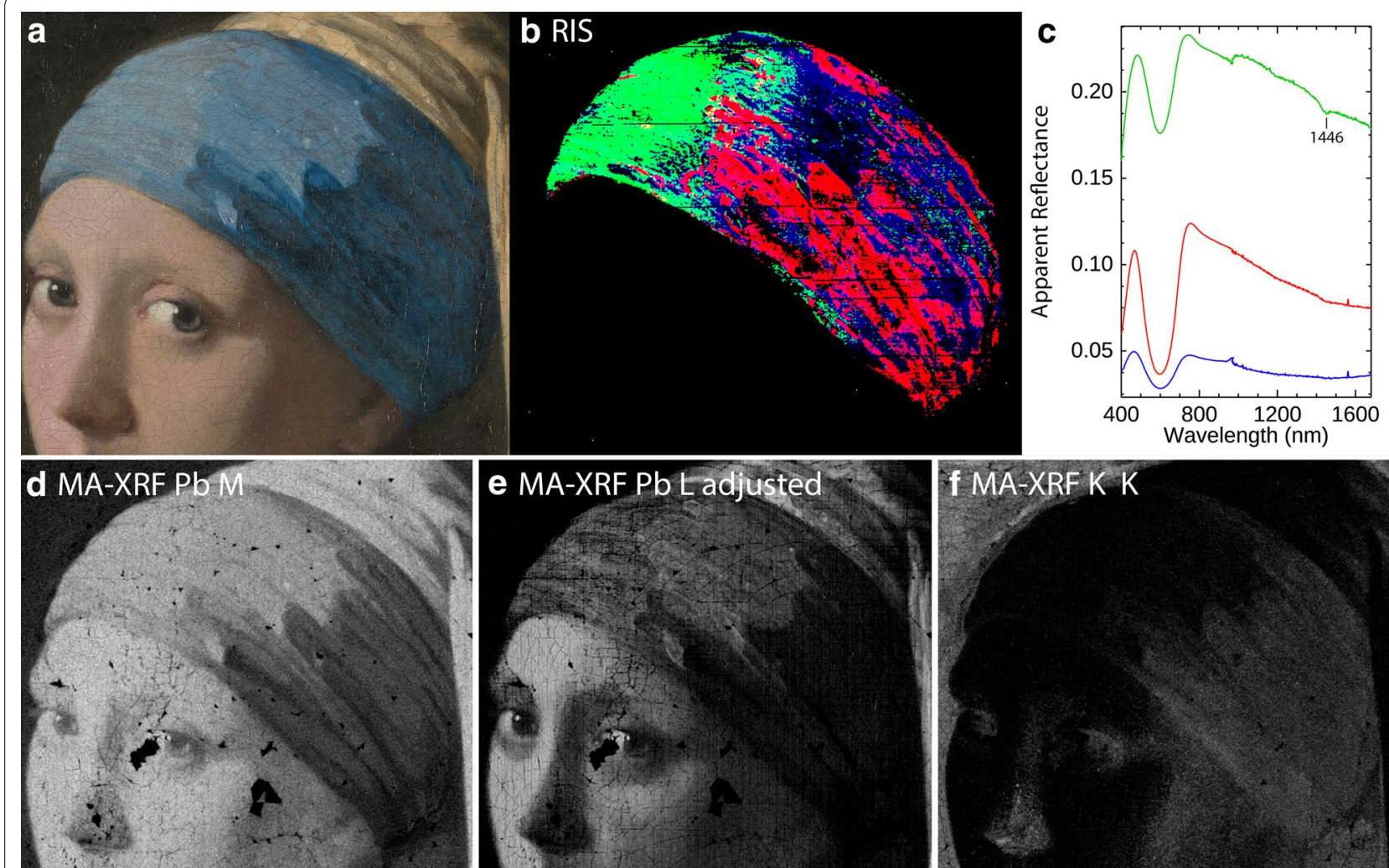

Fig. 4 a Visible light detail of blue headscarf. René Gerritsen Art \& Research Photography; b Maps made from the reflectance spectral endmembers (c) showing the use of ultramarine with varying amounts of lead white. $\mathbf{d}$ MA-XRF map of lead (Pb M); e MA-XRF map of lead (Pb L) with intensity adjusted to emphasise presence of lead in the face and headscarf rather than the background; $\mathbf{f}$ MA-XRF map of potassium (K K)

While the RIS image cube is useful for determining the distribution of ultramarine, in this case it is harder to discern the distribution of lead white due to absorption from the dark underlayer and ground. Still, the RIS map shows three zones: the 'green' has the most lead white, the 'red' has an intermediate amount, and the 'blue' region has little. The MA-XRF Pb M map (Fig. 4d) follows a similar pattern as the RIS maps, confirming that the lead white is mixed with ultramarine paint. The distribution of lead in the $\mathrm{Pb} \mathrm{L}$ map (Fig. 4e), representing the lower paint layers does not mirror the intensity in the colour image, RIS map, or the MA-XRF Pb M map which is consistent with the hypothesis that the colour of the blue headscarf was adjusted by incorporating more or less lead white. In regions where the MA-XRF potassium (K) map (Fig. 4f) overlaps with the RIS maps, it is a strong indication that the potassium is due to the pigment natural ultramarine. However, the $\mathrm{K}$ map does not directly indicate the amount of natural ultramarine, since the weak-to-non-existent $\mathrm{K}$ signal in the areas with more lead white (i.e. the top of the headscarf) is a consequence of matrix effects (i.e. absorption of X-ray excitation or emission).

\section{Yellow part of headscarf}

Groen et al's [6] analysis of a cross-section from a highlight in the yellow 'tail' of the headscarf (sample $1687 / 28$ ) found lead white and yellow earth pigments in the yellow paint layer. The MA-XRF element map for iron (Fe K) shows a varied distribution of iron within the yellow tail of the headscarf (Fig. 5b), with the highest amount detected in the darkest areas. The lighter yellow areas (Fig. 5a) have a larger amount of lead (Pb M) (Fig. 5f), and the iron levels are lower than expected, perhaps for the same reason as in the face discussed above. Analysis of the RIS cube resulted in two reflectance endmember spectra that describe the yellow part of the headscarf (Fig. $5 \mathrm{~d}$ inset). Both reflectance spectra show the characteristic features of yellow ochre, specifically, an absorption at $\sim 470 \mathrm{~nm}$, a transition edge at about $530 \mathrm{~nm}$, as well as broad absorptions at $\sim 665 \mathrm{~nm}$ and $\sim 946 \mathrm{~nm}$ resulting in a local reflectance maximum near $750 \mathrm{~nm}$. The FORS spectra collected from the same sites show the same spectral features, which indicate the presence of goethite $(\mathrm{FeOH} \cdot \mathrm{OH})$, associated with yellow ochre $[10,11]$. 

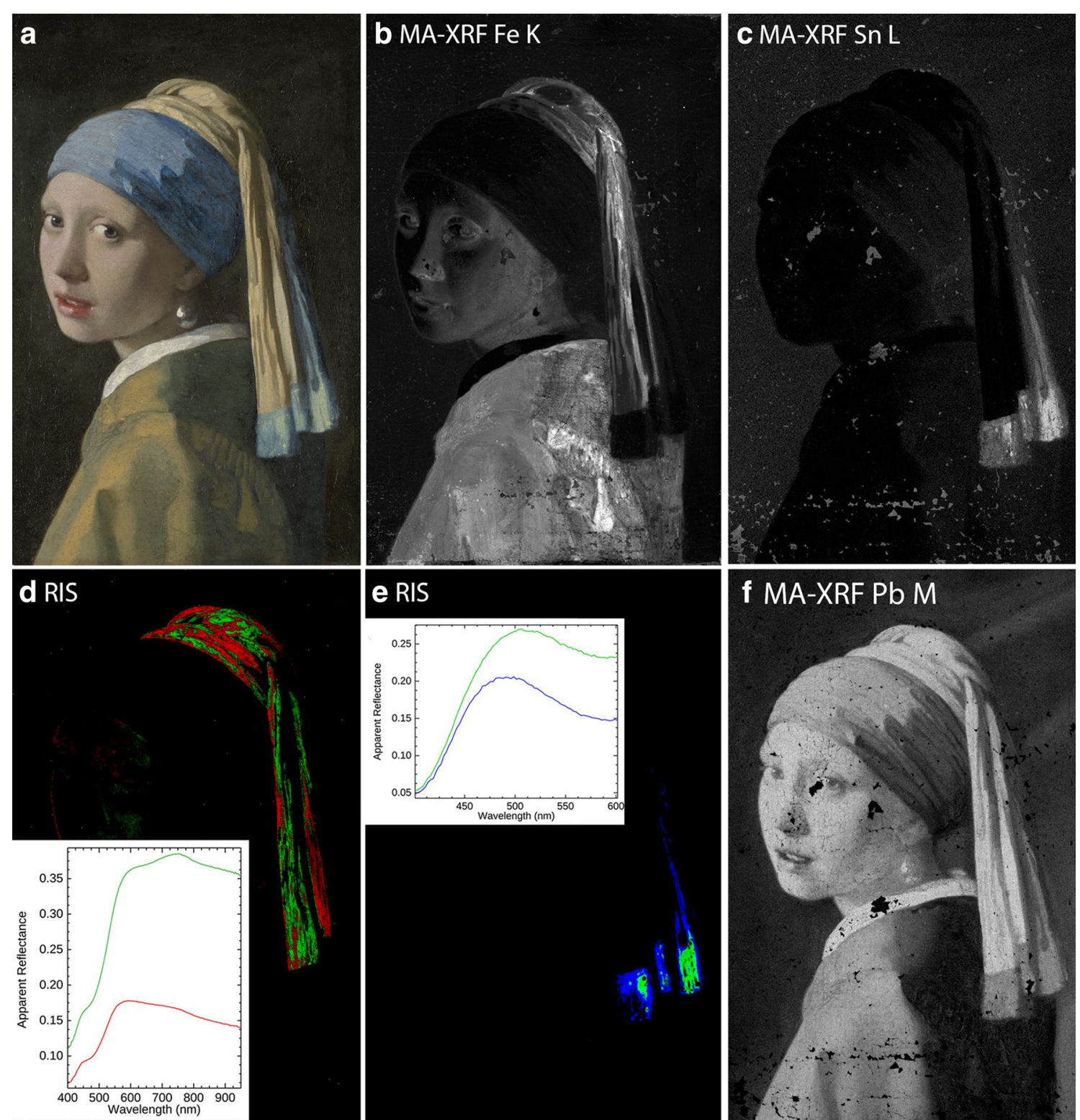

Fig. 5 a Visible light detail. René Gerritsen Art \& Research Photography; b MA-XRF map of iron (Fe K); c MA-XRF map of tin (Sn L); d Map of reflectance endmember spectra (spectra displayed in inset) showing distribution of ochre in the headscarf; e Map of reflectance endmember spectra (spectra displayed in inset) showing distribution of ultramarine with different amounts of yellow pigment (likely lead tin yellow) in border of headscarf; $\mathbf{f}$ MA-XRF map of lead (Pb M)

The spectral differences between the two endmembers relate to the amount of lead white, and the degree to which the dark underlayer absorbs the NIR light, as noted above. Consistent with the MA-XRF lead (Pb M) map (Fig. 5f), the light-yellow areas in the headscarf ('green' endmember, Fig. 5d) have reflectance spectra with a narrow absorption feature at $1449 \mathrm{~nm}$ attributable to basic lead white (hydrocerussite). In the darker areas, the MA$\mathrm{XRF} \mathrm{Pb} \mathrm{M}$ map shows less lead, which is consistent with the RIS 'red' endmember (Fig. 5d) having a weak $1449 \mathrm{~nm}$ absorption feature. There is an overall decrease in reflectance at wavelengths greater than about $600 \mathrm{~nm}$ likely from absorption by a dark underlayer.

\section{Border of headscarf}

The colour image (Fig. 5a) shows that the bottom edge of the headscarf has a border, where the colour ranges from blue to yellow-green. The RIS reflectance spectra 
from the border have maxima that vary between 490 and $507 \mathrm{~nm}$ and an absorption centred at $600 \mathrm{~nm}$ (Fig. 5e inset). The blue-coloured areas of the headscarf border have reflectance spectra similar to those from the blue part of the headscarf, indicating the presence of ultramarine. In the yellow-green areas, the $600 \mathrm{~nm}$ absorption, as well as the shift of the reflectance maximum to $507 \mathrm{~nm}$, suggests a yellow pigment was added to ultramarine to achieve the yellow-green colour (Fig. 5e inset). The border of the headscarf contains tin, as seen in the MA-XRF map for tin (Sn L) (Fig. 5c), which indicates that the yellow pigment is likely leadtin yellow.

Two RIS endmembers from the border of the headscarf were chosen manually. The endmember with a reflectance maximum at $490 \mathrm{~nm}$ ('blue' spectrum, Fig. 5e inset) maps to areas that overlap with moderate amounts of tin (Fig. 5e). The endmember with a greenshifted reflectance maximum ('green' spectrum, Fig. 5e inset) maps to areas having the largest amount of tin (Fig. 5e). Lead white is also present in the border of the headscarf, based on the NIR absorption at $1449 \mathrm{~nm}$ in the reflectance spectra, as well as the lead distribution in the MA-XRF $\mathrm{Pb} \mathrm{M}$ map. In summary, the imaging results are consistent with a mixture of ultramarine, lead-tin yellow, and lead white to achieve the colour nuances ranging from blue to yellow-green in the border of the headscarf.

\section{Yellow jacket}

In visible light, the colour of the Girl's jacket changes from a warm yellow-brown on the front (lit) side to a greenish-blue shadow on her back. Cross-sections from the light yellow paint taken in the 1990s were examined using light microscopy, which found that the upper layer included: lead white, yellow ochre, and ultramarine. Cross-sections taken from the back of the jacket contained yellow ochre, ultramarine, black, and a small amount of red lake [6].

The combination of MA-XRF and RIS offer the ability to determine the distribution of the pigments that had been identified in cross-sections. The MA-XRF results show that the entire jacket contains iron (Fe $\mathrm{K}$ ) (Fig. 6f), but only the front (lit) side contains lead (Pb L) (Fig. 6e). The areas of the jacket with the most iron correspond to the cartridge pleating on the back of her shoulder. Analysis of the RIS image cube yielded two reflectance endmembers that describe the front of the jacket (Fig. 6c). The first reflectance endmember ('green' spectrum) has absorption features similar to those of the yellow paint found in the headscarf: yellow ochre mixed with lead white (Fig. 5d inset). The identity of the yellow ochre pigment-goethite-was confirmed with FORS

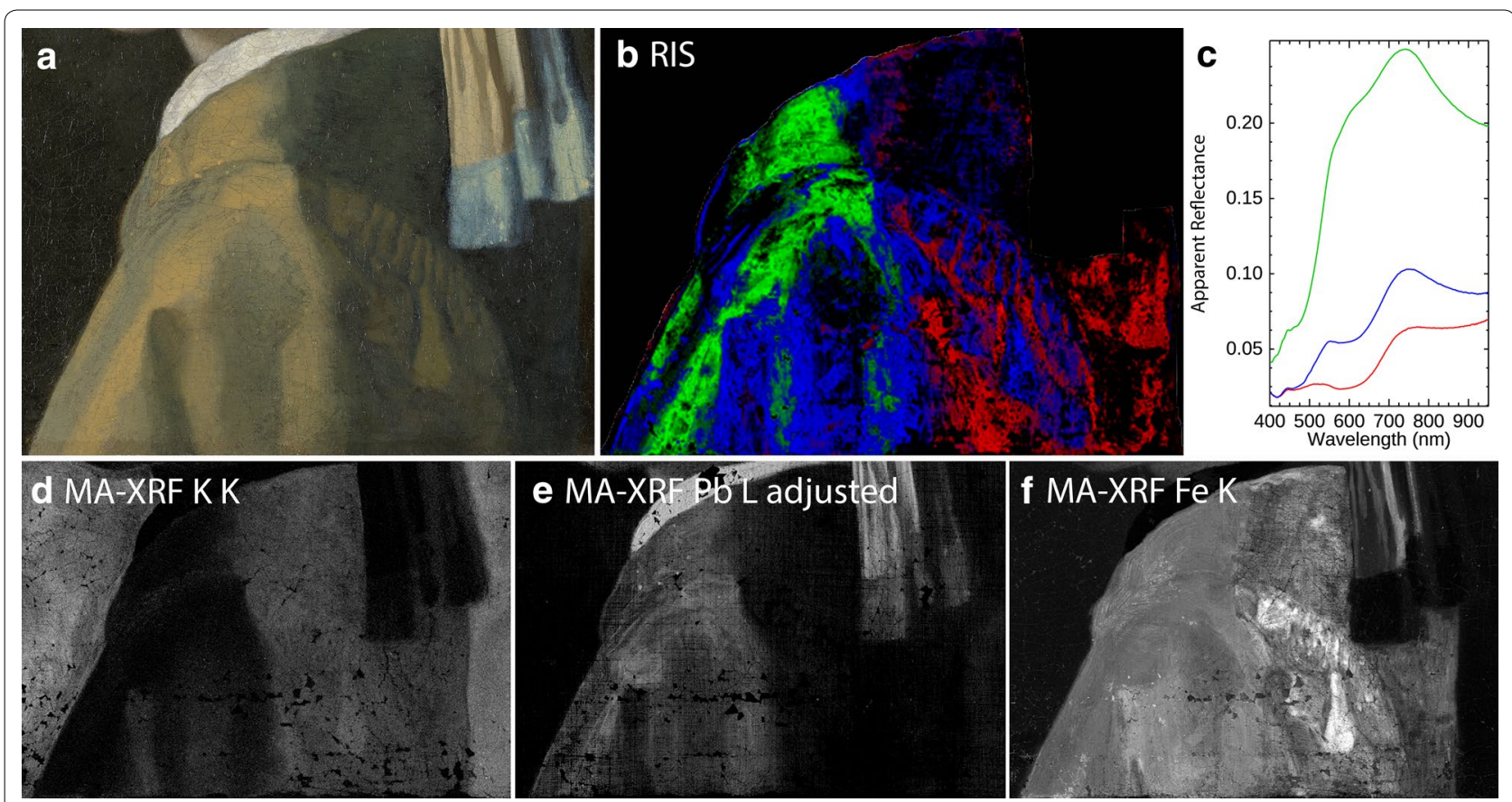

Fig. 6 a Visible light detail of yellow jacket. René Gerritsen Art \& Research Photography; b Map of reflectance endmember spectra, 'green'=yellow ochre, 'blue' = yellow ochre with ultramarine, 'red'= ultramarine with some yellow ochre and a hypothesised red pigment; c Reflectance endmember spectra used to make map in $\mathbf{b}$. $\mathbf{d}$ MA-XRF map of potassium (K K); e MA-XRF map of lead (Pb L); $\mathbf{f}$ MA-XRF map of iron (Fe K) 
measurements. This endmember maps to yellow areas on the front of the jacket (Fig. 6b). The second endmember ('blue' spectrum, Fig. 6c) is similar to the first but has lower reflectance, and shows absorption features indicative of yellow ochre altered by a broad, strong absorption at $600 \mathrm{~nm}$ that is characteristic of ultramarine. At the front of the jacket, this endmember maps to the dark-coloured folds in her sleeve (Fig. 6b). In visible light, these areas have a cooler, somewhat ruddy blue-green colour. Thus, RIS and MA-XRF maps show that the front (lit) side of the jacket was painted with lead white, yellow ochre and ultramarine blue, consistent with the earlier results from the prior analysis of cross-sections.

The back of the jacket, which is in shadow, also is partly described by the 'blue' endmember (yellow ochre and ultramarine), namely the brighter areas within the cartridge pleating. However, the darker folds within the cartridge pleating, as well as the very back of the jacket, is mapped by the 'red' endmember (Fig. 6b). The 'red' endmember is spectrally similar to the 'blue' endmember, but there is an additional absorption in the region of $460-580 \mathrm{~nm}$, indicating the presence of a red-absorbing component. Because analysis of a cross-section known to come from the back of the jacket identified the presence of red lake (cross-section 1687/22 described in Groen et al. [6]), the MA-XRF potassium (K) map was examined to show the possible distribution of this lake (Fig. 6d). Unfortunately, because $\mathrm{K}$ is also present in natural ultramarine, the interpretation of the $\mathrm{K}$ map is not straightforward. Thus, FIS was used to directly investigate the presence of red lake in the jacket.

Analysis of the FIS data cube obtained using UV excitation revealed fluorescence throughout the headscarf, face, and jacket, as evidenced by a false-colour emission image (R-725, G-650, B-575 nm) in Fig. 7b. Based on the deep red emission wavelength shown in the falsecolour image (i.e. $725 \mathrm{~nm}$ ), the fluorescence emission that appears pink, such as that in the headscarf and the jacket, could suggest the presence of a red lake pigment. However, inspection of the three types of emission spectra in the jacket (Fig. 7d) better inform the interpretation of the false-colour image. One spectrum displayed an emission shoulder near $620 \mathrm{~nm}$ ('red' spectrum, Fig. 7d), and is observed in the dark areas of the cartridge pleating on her sleeve. Another spectrum displayed an emission shoulder near $707 \mathrm{~nm}$ ('blue' spectrum, Fig. 7d), which coincides with areas rich in ultramarine. Both of the emission shoulders appear to be riding on an overall background that shows a decreasing emission intensity with increasing wavelength, described by the 'green' spectrum in Fig. 7d. These three types of emission spectra can be seen in other parts of the painting besides the jacket. The decreasing fluorescence emission intensity is observed in the Girl's neck, areas of the white collar, and the yellow parts of the headscarf (see false-colour fluorescence image, Fig. 7b). The emission shoulder at $707 \mathrm{~nm}$ is most apparent in regions of the blue parts of the headscarf. Interestingly, the $620 \mathrm{~nm}$ emission shoulder observed in the jacket is similar to the emission spectra seen in the lips (Fig. 2), identified as a red lake.

Since the emission cube is not corrected for selfabsorption, the emission shoulder observed at $707 \mathrm{~nm}$ is likely due to a filtering effect: specifically, spectrally broad fluorescence emission being selectively filtered by ultramarine. The spectrally broad fluorescence from the varnish, lead white, and other materials within the paint (see above) can be absorbed by ultramarine. As ultramarine becomes more reflective near $700 \mathrm{~nm}$, this results in a pseudo-emission peak observed in the fluorescence spectra, and is what mainly gives rise to the pink-coloured 'emission' in the false-colour image). To test this hypothesis, the FIS cube was fit using a linear combination of emission endmember spectra derived from regions of the FIS cube. These emission spectra were generated by first selecting spectra from areas of the emission cube where the above spectral features were strong: the $620 \mathrm{~nm}$ shoulder from the lips, the $707 \mathrm{~nm}$ shoulder from the blue headscarf, and the decreasing fluorescence from the front of the neck. Since the fluorescence emission is modelled as a linear function, to generate the pure 'endmembers', a scaled version of the spectrum with decreasing fluorescence ('green' dashed spectrum, Fig. 7e) was subtracted from the emission spectra associated with the $620 \mathrm{~nm}$ and $707 \mathrm{~nm}$ features to create endmember spectra (Fig. 7e). These three endmember spectra were used to perform linear unmixing, which produces three images whose intensity values are proportional to the amount of the endmember present. These images in the region of the jacket are shown in Fig. 7c.

The endmember representing areas of decreasing reflectance ('green' dashed spectrum, Fig. 7e) maps strongly to the yellow and blue parts of the headscarf, as well as to the regions of the front lit side of the jacket that are rich in ochre (Fig. 7c). The endmember with the peak at $707 \mathrm{~nm}$ ('blue' spectrum, Fig. 7e) maps most strongly to the blue border of the headscarf known to contain ultramarine (seen at the top of the map in Fig. 7c). This endmember also maps to darker regions of the sleeve and front of the jacket that contain ultramarine and ochre. The map is strong evidence that this spectral feature is a pseudo-emission peak resulting from absorption by ultramarine, and not an actual fluorescent pigment with an emission at $707 \mathrm{~nm}$. Finally, the endmember with a fluorescence emission at $620 \mathrm{~nm}$ ('red' spectrum, Fig. 7e) maps most strongly to the backside of the jacket that is in shadow, including the entire area along her back and 

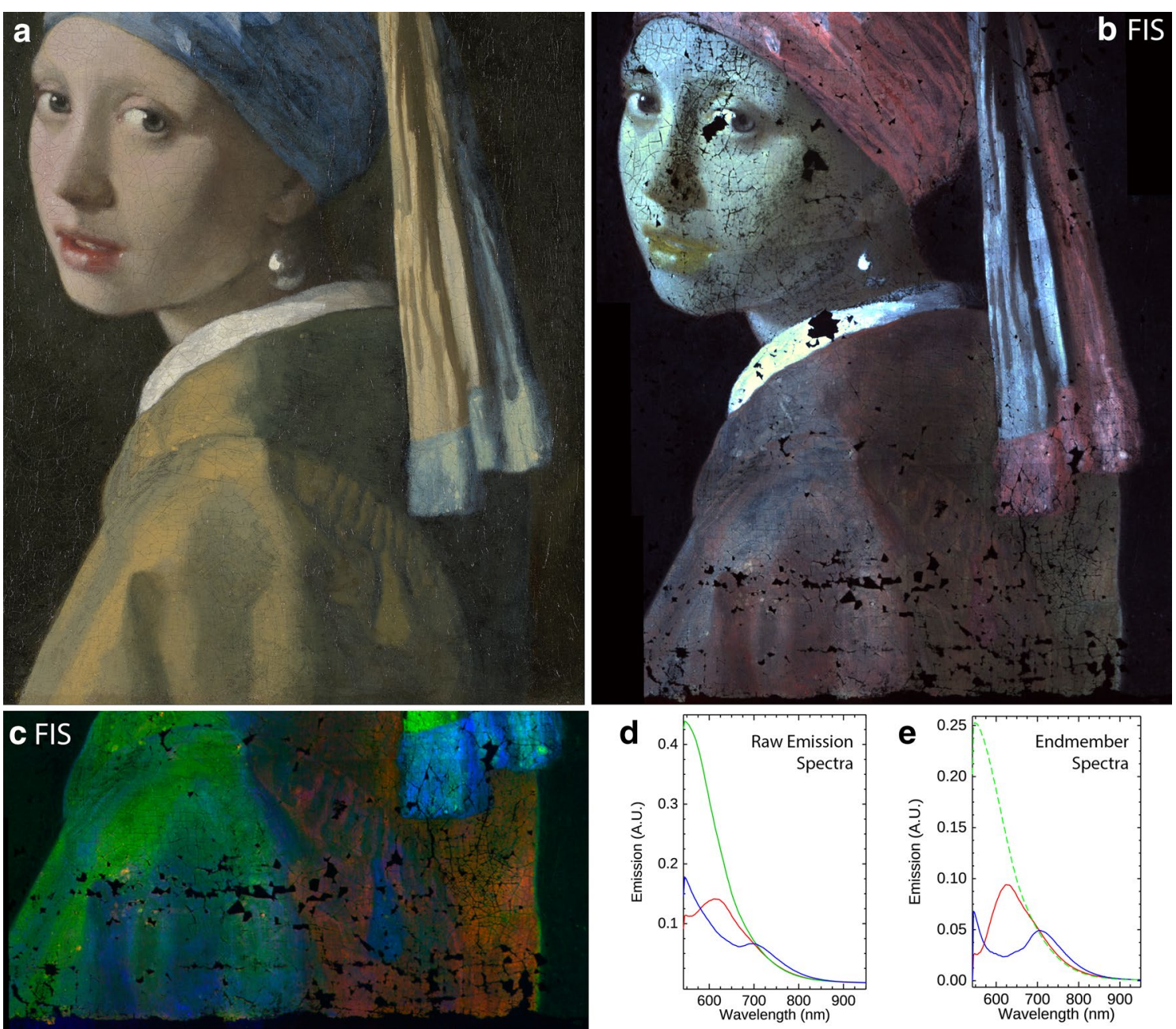

Fig. 7 a Visible light detail of face and clothing. René Gerritsen Art \& Research Photography; b false-colour UV-induced fluorescence image (RGB: 725,650 , and $575 \mathrm{~nm}$ ); c False-colour spectral unmixing map displaying the distribution of fluorescence endmember spectra shown in $\mathbf{e}$, including the 'red' endmember with $620 \mathrm{~nm}$ emission peak, the 'blue' endmember with $707 \mathrm{~nm}$ emission peak, and the 'green' endmember with a slowly decreasing emission intensity; $\mathbf{d}$ raw fluorescence emission spectra from the FIS data cube from which the endmember spectra (e) were calculated to make the map in c; e Endmembers used for spectral unmixing. The 'red' and 'blue endmembers were calculated by subtracting off a scaled spectrum of the component with slowly decreasing emission, shown with a'green'dashed line

the dark regions of the cartridge pleating on the back of her sleeve (Fig. 7c). The $620 \mathrm{~nm}$ emission is likely due to the presence of a red lake in the shadowed areas that are part of the pleats, consistent with the previous analysis of cross-sections. The MA-XRF K map does not show the details of the pleats, likely due to the presence of natural ultramarine in this region of the jacket.

\section{Background}

The dark background surrounding the Girl was the focus of earlier research to understand its original appearance. Groen et al. [6] analysed cross-sections to determine the stratigraphy of the background: a black underlayer and a glaze. Light microscopy of a cross-section from the left-hand side of the painting showed that the glaze was greenish. In two cross-sections from the lower right, the glaze was yellowish-brown-green: the colour was hypothesised to be related to the degradation of the glaze. Because the glaze was found to contain weld (a yellow lake) and indigo, they hypothesised the background was made with an "even, smooth, glossy, translucent, hard green paint, made to look darker and given depth by a dark underpaint."

New research from the 2018 Girl in the Spotlight project confirmed that an infrared-absorbing underlayer lies beneath the entire background [20]. Vandivere et al. 
[21] determined the composition of this underlayer from three re-analysed cross-sections: it is predominately charcoal, based on the presence of carbon and the appearance of splintery particles. They also confirmed that the glaze in a sample from the lower right-one that was also examined by Groen et al. [6] -appears yellowish with transparent blue spots. In addition, some of the elements detected in the glaze layer of the cross-sections were lead, copper, potassium, and calcium.

Macroscopic examination of Girl with a Pearl Earring visualised the distribution of some of these elements in the background. The MA-XRF lead (Pb M) map (Fig. 8f) revealed distributions that suggest the presence of diagonal lines-possibly depicting a curtain - on the right side of the painting, hypothesised to be from modelling with lead white present in the glaze. In this paper, visible-toNIR RIS (400-1680 nm) was used to examine the colour properties of the glaze across the painting surface by examining the variation in the reflectance spectra in the visible spectral region, as well as in the infrared region. The latter is expected to be dominated by the carbon black (charcoal-containing) underlayer.

To obtain reflectance spectra from 400 to $1680 \mathrm{~nm}$ with adequate signal-to-noise, the RIS image cube was spatially aggregated $(5 \times)$ in order to reduce the random noise. To remove specular highlights from the illumination, a median filter was used $(3 \times 3$ pixels). Extraction of endmember spectra that described the background using multivariate methods was not successful and so other methods were used to document the degree of variation
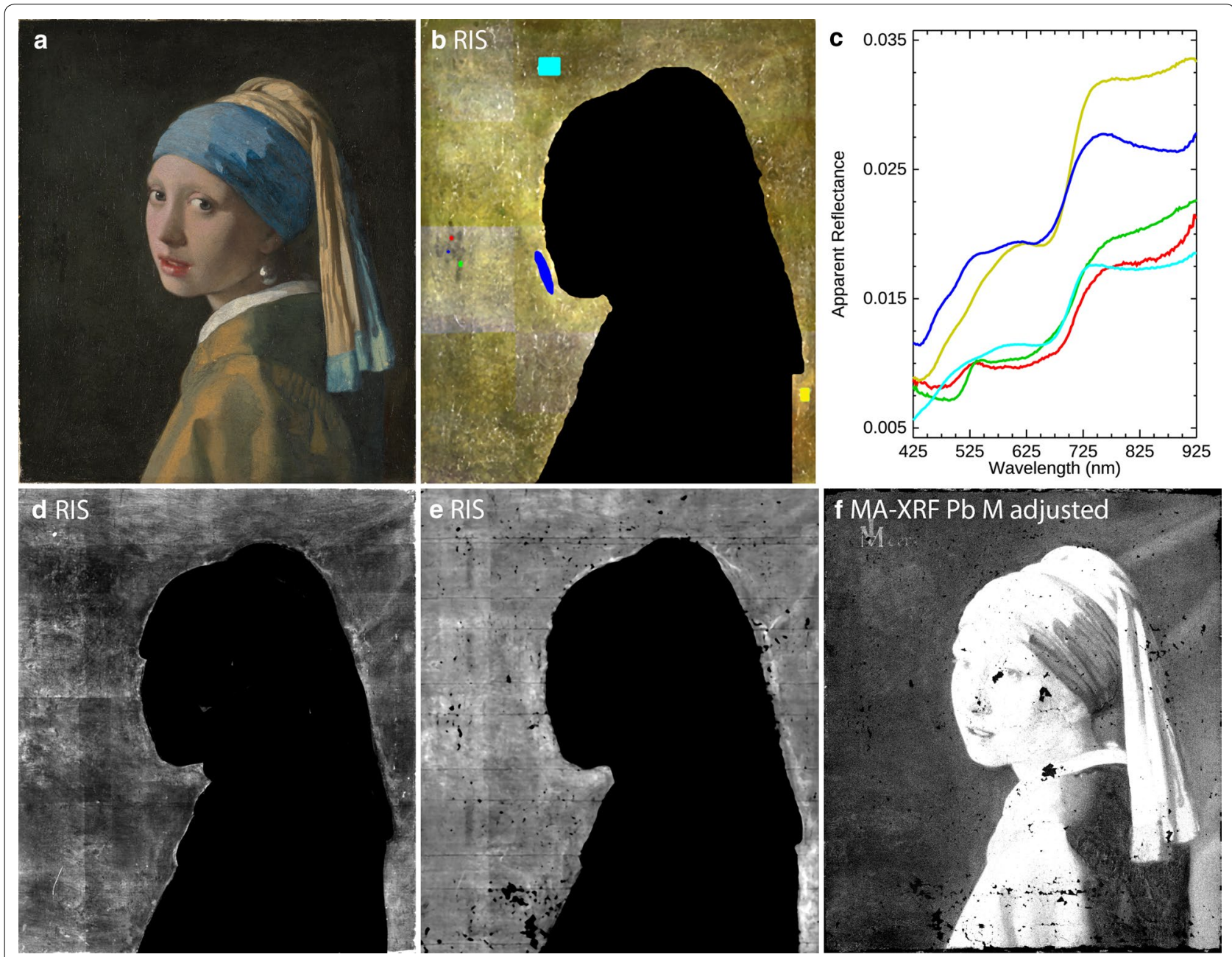

Fig. 8 a Visible light photograph. René Gerritsen Art \& Research Photography; b False-colour reflectance image (RGB: 608, 504, 450 nm) showing values from 0 to $3 \%$ apparent reflectance. The region of the figure was masked; $\mathbf{c}$ average reflectance spectra from five regions of interest shown in b; d NIR reflectance image averaged from 725 to 925 nm; e image showing difference in reflectance between two NIR spectral regions: 1600$1680 \mathrm{~nm}$ and 1000-1200 nm; f MA-XRF map of lead (Pb M) (thresholded to emphasise the background) 
in the reflectance spectra. The first was to make a falsecolour composite image (Fig. 8b) using the reflectance values in the visible spectral region at $450 \mathrm{~nm}$ (blue channel), 504 nm (green channel) and $608 \mathrm{~nm}$ (red channel). In this false-colour image, the histogram for each band was set to display values from 0 to $3 \%$ apparent reflectance in order to best visualise the variation in reflectance among the three wavelengths. This gives an image that is a blotchy khaki colour, where the variation in the falsecolour ranges from yellow-green to brown, and smaller regions are brighter or darker.

The average reflectance spectrum from selected bright and dark areas-regions of interest (ROI): 'blue', 'yellow', 'aqua,' 'green', 'red'-are shown in Fig. 8c. The colour of the spectra corresponds with the coloured ROIs shown in the false-colour image in Fig. 8b. The 'blue,' 'yellow', and 'aqua' regions have spectra that show a gradual increase in reflectance from $\sim 430$ to $650 \mathrm{~nm}$, a sharper increase in reflectance at $705 \mathrm{~nm}$ that is consistent with the inflection point of indigo as it becomes transparent, and relatively low, constant reflectance in the NIR. The low reflectance at NIR wavelengths, as compared to spectra from the figure, is interpreted as being from the black underlayer and the ground assuming there are no other pigment particles in the glaze layer. The average spectra from these three ROIs are representative of most of the background. Two of the ROIs ('green', 'red') have a reflectance maximum at $\sim 525 \mathrm{~nm}$ that indicate a greencoloured paint (Fig. 8b, c). These ROIs are from areas that became apparent after removal of old retouching during the 1994 restoration, as the areas appeared darker (lower overall reflectance) and more saturated than the surrounding region. Because these darker areas were protected from light, the glaze in these regions is thought to be better preserved [6]. The spectral features from these two ROIs are found in only a small portion of the background. Thus, much of the background does not have an obvious green reflectance. This is likely due to the degradation of the weld pigment [6].

The brightness variation (i.e. overall reflectance value) over the surface is correlated between images describing two different spectral ranges: the visible (Fig. 8b) and initial part of the NIR (average of 725-925 nm, Fig. 8d). In the visible spectral region (Fig. 8b), there is an increase in the average reflectance around the face of the Girl, the top right and left corners, and the narrow strip along the edge of her back at bottom right. The darkest areas are the lower left. The difference in the reflectance is small, about 1 to $2 \%$. A similar pattern is observed in the reflectance image averaged from 725 to $925 \mathrm{~nm}$ (Fig. 8d). The range of brightness in this spectral range is $\sim 2$ to $4 \%$. In this spectral region, a glaze layer containing weld and indigo is expected to be transparent, and thus only the dark underlayer should contribute to the observed reflectance. To explore whether the dark underlayer is the only contributor to the observed NIR reflectance, the NIR spectral region from 1000 to $1680 \mathrm{~nm}$ in the RIS image cube was examined to determine if the reflectance varies over this range of longer wavelengths. The difference in reflectance was taken between two images, where the reflectance intensity was averaged from 1000 to $1200 \mathrm{~nm}$ and 1600 to $1680 \mathrm{~nm}$, and the resulting difference image is shown in Fig. 8e. This image shows the same spatial variation seen in the image from 725 to $925 \mathrm{~nm}$, which indicates the reflectance falls off slowly with increasing NIR wavelengths. The data suggests that the source of the intensity variation is a light-scattering white pigment such as lead white, as charcoal is equally absorbing in the NIR and should have constant reflectance. The spatial variation in brightness seen in the RIS data agrees with the pattern observed in MA-XRF Pb M map (Fig. 8f). The diagonal lines visible in the lead map has been interpreted as the modelling of a possible draped fabric, such as a curtain [21]. Groen et al. [6] reported the presence of a little lead white in the glaze. This was confirmed during the 2018 re-examination of the cross-sections. This led Vandivere et al. [21] to conclude that the pattern observed in the MA-XRF Pb M map is due to small additions of lead white in the glaze to vary the colour on the right side of the background. The RIS results lend support to this hypothesis and provide a more complete understanding of the colour variation in the glaze layer of the background.

\section{Conclusion}

The goal of the macroscale analyses described in this paper was to determine the distribution of pigments and pigment mixtures used by Vermeer in Girl with a Pearl Earring. The new results from spectral imaging modalities-including RIS, FIS, and MA-XRF-were compared with those from prior and recent re-analyses of crosssections from various sites on the painting (although the cross-section locations did not include all colour areas of the painting). The pigment maps show that Vermeer made extensive use of yellow ochre and ultramarine to paint the headscarf as well as the jacket, and he added a red lake to the areas of the jacket meant to be in relative shadow. The flesh tones contained lead white, vermilion, and ochre, with additional red lake used for the lips and cheek. The visible brightness of the background has now been quantified, having an overall reflectance of only 1 to $3 \%$. Indigo was found throughout the background, and small green areas (i.e. reflectance maximum at $525 \mathrm{~nm}$ ) coincided with areas previously protected by old retouchings, and thus better preserved. Although some of the pigments detected here were known previously, the 
spectral imaging modalities used in this study provided a better understanding of their distribution. In particular, the distribution of a red lake pigment in the Girl's face and jacket has now been mapped.

The cross-sections and maps suggest that Vermeer's pigment mixtures were well thought out, and that he intended that they create a specific effect. Each colour area was built up separately, with a distinct layer structure. The pigment mixtures are 'clean', in the sense that they contain a limited number of pigments with specific optical properties. Whereas the light parts of the composition that face the light contain opaque pigmentssuch as lead white, vermilion, and lead-tin yellow-the shadows incorporate more translucent pigments, such as organic lakes. This fits with our understanding of Vermeer as a quick but careful painter who had a profound understanding of the optical and handling properties of his materials.

\section{Experimental methods}

\section{Hyperspectral imaging cameras}

Visible-to-near-infrared (VNIR, 400-1000 nm) diffuse reflectance and molecular fluorescence image cubes of Girl with a Pearl Earring were acquired with a high sensitivity hyperspectral line-scanning camera. The hyperspectral camera (modified SOC-730 model, Surface Optics Corporation, CA) consists of a $35 \mathrm{~mm}$ EFL lens (Xenoplan, Schneider Optics, Germany) and a transmission grating-prism spectrometer (model V10E, Specim, Finland) aligned to a high sensitivity, electron-multiplied, silicon CCD detection array (ProEM-1024, Princeton Instruments, NJ). The imaging spectrometer has a spectral sampling of $2.5 \mathrm{~nm}$, and produces image cubes with 1024 by 1024 spatial pixels and 280 spectral channels. Near-infrared (NIR, 967-1680 nm) diffuse reflectance image cubes were collected with a line-scanning hyperspectral camera (SOC-720 model, Surface Optics Corporation, CA) that utilises a transmission grating-prism spectrometer and a high sensitivity InGaAs detection array. The imaging spectrometer has a spectral sampling of $3.4 \mathrm{~nm}$, and produces image cubes with 640 by 640 spatial pixels and 256 spectral channels. Both hyperspectral cameras utilise internal scan mirrors to produce the image cubes.

A step/stare collection approach was used to collect VNIR and NIR image cubes of the entire painting to allow generating a complete image cube spanning the VNIR and NIR spectral regions. To do this, the camera and lights remained stationary and the painting was moved left and right on a specially-built easel (made by Rik Klein Gotink). Two different illumination systems were used to capture the reflectance image cubes. For the collection of VNIR reflectance image cubes, four Solux $4700 \mathrm{~K}, 50 \mathrm{~W}$ lamps (Solux $4700 \mathrm{~K}$, Taylor lighting, NY) were used, providing approximately 1200-1500 lx at the surface of the artwork. An exposure time of $150 \mathrm{~ms}$ per spatial-line was used to collect the 1024 lines in one image cube. The NIR reflectance image cubes were collected using two $150 \mathrm{~W}$ halogen $3000 \mathrm{~K}$ lamps (Osram) in a reflective housing with a diffusor (Lowel ViP Pro-Light). The voltage of the lamps was decreased by a rheostat in order to shift the colour temperature to a lower value. The measured visible light level at the painting surface was $\sim 700 \mathrm{~lx}$.

The conversion of the raw image cubes to apparent reflectance was done using a standard protocol. A dark image cube (no light allowed into the camera) was collected along with an image cube of the illumination light reflected off a white diffuse reflectance standard (99\% reflector, Labsphere, Inc) that was placed in the plane of the painting and was larger than the field of view of each camera. The apparent reflectance image cubes were calculated by dividing each raw cube collected of the painting after subtraction of the dark image cube by the image cube of the dark-subtracted diffuse reflectance standard.

For FIS measurements, the painting was illuminated using excitation light either from a UV lamp or from a slide projector (Ektagraphic III, Kodak, USA) with a $533 \mathrm{~nm}$ shortpass filter (533 nm blocking edge BrightLine SP, Semrock, USA) in the slide holder. A filter (460-540 nm bandpass filter) placed in front of the projection lens further limited the excitation spectral band from 460 to $532 \mathrm{~nm}$. The cut-on wavelength of the emission spectral band was determined by a $532 \mathrm{~nm}$ longpass interference filter (532 nm EdgeBasic LP, Semrock) placed on the foreoptic of the hyperspectral camera which prevented excitation radiation from entering the camera. The white diffuse reflectance standard was used to confirm little light leakage from the excitation light was collected. Under both illumination conditions, the fluorescence emission image cube and corresponding dark image cube of the painting were captured with an exposure time of $300 \mathrm{~ms}$ per line and an electron multiplying gain of 100 (which proportionally increased the collected photocharge before the CCD readout cycle). The same method for producing the apparent reflectance image cubes was followed: a dark image cube was subtracted from the raw fluorescence image cube. This was divided by a dark-corrected cube that consisted of replicated images of a uniform white surface (a sheet of white paper) that was placed in the plane of the painting. This procedure corrected for non-uniformity of the illumination and the effective variation in the throughput of the camera and converted the fluorescence emission image cube to 'relative spectral radiance'. 
The reflectance and fluorescence image cubes were then spatially registered to a reference colour image of the painting [22]. For the reflectance and first derivative maps shown, the identification and mapping procedure was completed using the ENVI Spectral Hourglass tool (Harris Corp.).

\section{Macroscopic X-ray fluorescence (MA-XRF)}

Macroscopic X-ray fluorescence maps of the entire painting were collected in two scanning sessions using a commercial XRF scanner (M6 Jetstream, Bruker) [23]. The scanner consists of a measuring head equipped with a $30 \mathrm{~W}$ rhodium-target microfocus X-ray tube, a polycapillary lens, and a $60 \mathrm{~mm}^{2}$ silicon drift detector (XFlash, Bruker) with a beryllium window (energy resolution $<145 \mathrm{eV}$ at $\mathrm{Mn}-\mathrm{K}_{\alpha}$ ). By moving the measuring head on the $X Y$-motorised stage at a constant speed $(3.2 \mathrm{~mm} / \mathrm{s})$, the painting is scanned pixel by pixel, line by line. With the MA-XRF scanner, only elements heavier than silicon can be detected. Scans were carried out at $50 \mathrm{kV}$ and a current of $600 \mu \mathrm{A}$, with a $400 \mu \mathrm{m}$ step size, and a dwell time of $125 \mathrm{~ms}$. The distance between the scanning head and the paint surface was set at $\sim 1 \mathrm{~cm}$, corresponding to an X-ray spot size of c. $250 \mu \mathrm{m}$. The two data cubes were exported as raw files, and element maps were made and stitched using PyMca and Datamuncher software [24].

\begin{abstract}
Abbreviations
FORS: fibre optic reflectance spectroscopy; FWHM: full width at half maximum; FIS: fluorescence imaging spectroscopy; HPLC: high performance liquid chromatography; MA-XRF: macroscopic X-ray fluorescence scanning; NIR: near infrared; RIS: reflectance imaging spectroscopy; ROI: region of interest; UV: ultraviolet; VNIR: visible-to-near-infrared.

\section{Acknowledgements}

The research project The Girl in the Spotlight is a Mauritshuis initiative, led by paintings conservator Abbie Vandivere, with a team of internationally recognised specialists working within the collaborative framework of the Netherlands Institute for Conservation+Art+Science+ (NICAS). Dr. Victor Gonzalez (TU Delft/Rijksmuseum) provided assistance with the collection of RIS and FIS measurements. The paintings conservation department at the Mauritshuis helped with logistics. René Gerritsen (Art \& Research Photography) did the technical photography. The authors gratefully acknowledge Drs. Melanie Gifford, Lisha Glinsman and Barbara Berrie for providing invaluable advice during the analysis of the various data sets.
\end{abstract}

\section{Authors' contributions}

JKD and KAD collected and processed the RIS and FIS image cubes and made the figures. AvL performed the MA-XRF data collection and made the element maps. AV coordinated the data collections and set up the painting, and provided important information from the earlier studies. JKD and KAD wrote the paper, and AV and AvL helped edit the text. All authors read and approved the final manuscript.

\section{Funding}

The Netherlands Institute for Conservation+Art+Science + funded the participation of the NICAS partners in the project, including use of analytical equipment and the time devoted to the project by scientists from the RCE, TU Delft, University of Amsterdam and the Rijksmuseum.
The Girl in the Spotlight project was made possible with support from the Johan Maurits Compagnie Foundation. JKD and KAD acknowledge support from the National Gallery of Art, Washington, D.C.

\section{Availability of data and materials}

The datasets used and/or analysed during the current study are available from the corresponding author on reasonable request.

\section{Competing interests}

The authors declare that they have no competing interests.

\section{Author details}

${ }^{1}$ Scientific Research Department, National Gallery of Art, 6th and Constitution Avenue NW, Washington, DC 20565, USA. ${ }^{2}$ Conservation Department, Mauritshuis, Plein 29, 2511 CS The Hague, the Netherlands. ${ }^{3}$ Conservation \& Science, Rijksmuseum, Hobbemastraat 22, 1017 ZC Amsterdam, the Netherlands.

Received: 3 October 2019 Accepted: 22 December 2019

Published online: 07 January 2020

\section{References}

1. Dooley KA, Conover DM, Glinsman LD, Delaney JK. Complementary standoff chemical imaging to map and identify artist materials in an early Italian renaissance panel painting. Angew Chem Int Ed. 2014;53:13775-9. https://doi.org/10.1002/anie.201407893.

2. Dooley KA, Gifford EM, van Loon A, Noble P, Zeibel JG, Conover DM, Alfeld M, Van der Snickt G, Legrand S, Janssens K, Dik J, Delaney JK. Separating two painting campaigns in Saul and David, attributed to Rembrandt, using macroscale reflectance and XRF imaging spectroscopies and microscale paint analysis. Herit Sci. 2018;6:46. https://doi.org/10.1186/ s40494-018-0212-3.

3. Legrand S, Alfeld M, Vanmeert F, De NolfW, Janssens K. Macroscopic Fourier transform infrared scanning in reflection mode (MA-rFTIR), a new tool for chemical imaging of cultural heritage artefacts in the mid-infrared range. Analyst. 2014;139:2489-98. https://doi.org/10.1039/c3an02094k.

4. The Feast of the Gods. Conservation, examination, and interpretation. Washington, D.C.: National Gallery of Art; 1990.

5. Dooley KA, Berrie B, Delaney JK. Appendix II: technical reexamination of the Feast of the Gods. In: Brown DA, editor. Giovanni Bellini: the last works. Milan: Skira Editore; 2019. p. 333-47.

6. Groen K, van der Werf ID, van den Berg KJ, Boon JJ. Scientific examination of Vermeer's "Girl with a Pearl Earring". In: Gaskell I, Jonker M, editors. Vermeer studies: studies in the history of art 55. New Haven: National Gallery of Art; 1988. p. 168-83.

7. Wadum J, Hoppenbrouwers R, van der Struick L. Vermeer illuminated. Conservation, restoration and research. Wormer: $V+K$ Publishing/ Inmerc; 1994

8. Vandivere A, Wadum J, van den Berg KJ, van Loon A, the Girl in the Spotlight research team. From 'Vermeer Illuminated' to 'The Girl in the Spotlight': approaches and methodologies for the scientific (re-)examination of Vermeer's Girl with a Pearl Earring. Herit Sci. 2019;7:66. https://doi. org/10.1186/s40494-019-0307-5.

9. Delaney JK, Zeibel JG, Thoury M, Littleton R, Palmer M, Morales KM, de la Rie ER, Hoenigswald A. Visible and infrared imaging spectroscopy of Picasso's Harlequin Musician: mapping and identification of artist materials in situ. Appl Spectrosc. 2010;64:584-94. https://doi.org/10.1366/00037 0210791414443.

10. Hunt GR, Salisbury JW, Lenhoff CJ. Visible and near-infrared spectra of minerals and rocks: III. Oxides and hydroxides. Modern Geol. 1971;2:195-205.

11. Scheinost AC, Chavernas A, Barrón V, Torrent J. Use and limitations of second-derivative diffuse reflectance spectroscopy in the visible to nearinfrared range to identify and quantify Fe oxide minerals in soils. Clays Clay Miner. 1998;46:528-36. https://doi.org/10.1346/ccmn.998.0460506.

12. van Loon A, Vandivere A, Delaney JK, Dooley KA, De Meyer S, Vanmeert F, Gonzalez V, Janssens K, Leonhardt E, Haswell R, de Groot S, D'Imporzano P, Davies GR. Beauty is skin deep: the skin tones of Vermeer's Girl with a Pearl Earring. Herit Sci. 2019;7:102. https://doi.org/10.1186/s4049 4-019-0344-0. 
13. Bisulca C, Picollo M, Bacci M, Kunzelman D, editors. UV-Vis-NIR reflectance spectroscopy of red lakes in paintings. In: 9th international conference on NDT of Art; 2008; Jerusalem, Israel. https://www.ndt.net/article/art2008/ papers/199Bisulca.pdf.

14. Delaney JK, Dooley KA, Radpour R, Kakoulli I. Macroscale multimodal imaging reveals ancient painting production technology and the vogue in Greco-Roman Egypt. Sci Rep. 2017;7:15509. https://doi.org/10.1038/ s41598-017-15743-5.

15. Clementi C, Miliani C, Verri G, Sotiropoulou S, Romani A, Brunetti BG, Sgamellotti A. Application of the Kubelka-Munk correction for selfabsorption of fluorescence emission in carmine lake paint layers. Appl Spectrosc. 2009;63:1323-30. https://doi.org/10.1366/000370209790109 058.

16. Clementi C, Doherty B, Gentili PL, Miliani C, Romani A, Brunetti BG, Sgamellotti A. Vibrational and electronic properties of painting lakes. Appl Phys A. 2008;92:25-33. https://doi.org/10.1007/s00339-008-4474-6.

17. Verslype I. The restoration of "Woman in Blue Reading a Letter" by Johannes Vermeer. Rijksmus Bull. 2012;60:2-19.

18. Gifford EM, Glinsman LD. Collective style and personal manner: materials and techniques of high-life genre painting. Vermeer and the masters of genre painting: inspiration and rivalry. New Haven: Yale University Press; 2017. p. 64-83.

19. Plesters J. Ultramarine blue, natural and artificial. In: Roy A, editor. Artists' pigments: a handbook of their history and characteristics, vol. 2. Washington: National Gallery of Art; 1993. p. 37-65. https://www.nga.gov/resea rch/publications/pdf-library/artists-pigments-vol2.html.
20. Vandivere A, van Loon A, Dooley KA, Haswell R, Erdmann RG, Leonhardt E, Delaney JK. Revealing the painterly technique beneath the surface of Vermeer's Girl with a Pearl Earring using macro- and microscale imaging. Herit Sci. 2019;7:64. https://doi.org/10.1186/s40494-019-0308-4.

21. Vandivere A, van Loon A, Callewaert T, Haswell R, Proaño Gaibor AN, van Keulen $\mathrm{H}$, Leonhardt E, Dik J. Fading into the background: the dark space surrounding Vermeer's Girl with a Pearl Earring. Herit Sci. 2019;7:69. https ://doi.org/10.1186/s40494-019-0311-9.

22. Conover DM, Delaney JK, Loew MH. Automatic registration and mosaicking of technical images of Old Master paintings. Appl Phys A. 2015;119:1567-75. https://doi.org/10.1007/s00339-015-9140-1.

23. Alfeld M, Pedroso JV, van Eikema Hommes M, Van der Snickt G, Tauber G, Blaas J, Haschke M, Erler K, Dik J, Janssens K. A mobile instrument for in situ scanning macro-XRF investigation of historical paintings. J Anal Atom Spectrom. 2013;28:760-7. https://doi.org/10.1039/c3ja30341a.

24. Alfeld M, Janssens K. Strategies for processing mega-pixel X-ray fluorescence hyperspectral data: a case study on a version of Caravaggio's painting Supper at Emmaus. J Anal Atom Spectrom. 2015;30:777-89. https ://doi.org/10.1039/c4ja00387j.

\section{Publisher's Note}

Springer Nature remains neutral with regard to jurisdictional claims in published maps and institutional affiliations.

\section{Submit your manuscript to a SpringerOpen ${ }^{\odot}$ journal and benefit from:}

- Convenient online submission

- Rigorous peer review

- Open access: articles freely available online

- High visibility within the field

- Retaining the copyright to your article

Submit your next manuscript at $\boldsymbol{\nabla}$ springeropen.com 